\title{
Pregnancy Outcomes in Patients with Anovulatory Infertility in Different Ovulation Induction Programs
}

\author{
SHAOHUA LIN* \\ Reproductive Center, Guangxi International Zhuang Nationality Hospital, No. 8 Qiuyue Road, Wuxiang New District, Nanning \\ City 532021, Guangxi Province, China
}

Lin et al.: Effect of different ovulation induction programs on patients with ovulatory infertility

\begin{abstract}
This study aims to explore the treatment effect of different ovulation induction programs on patients with ovulatory infertility, for which 82 infertility patients who visiting our hospital from January 2013 to December 2018 were elected for sampling. All patients were divided into an experimental group and a control group according to the random number table method, with 41 cases in each group. The experimental group was treated with letrozole and clomiphene therapy; the control group was only treated with letrozole. The clinical comprehensive efficacy, ovulation rate and pregnancy rate of the two groups were compared in the study. The result shows that after the treatment, the ovulation rate and pregnancy rate of the two groups were significantly higher than those before treatment, and the experimental group was significantly better than the control group $(\mathbf{p}<\mathbf{0 . 0 5})$. It is found that, for patients with ovulatory infertility who were treated with both letrozole and clomiphene therapy, their endometrial thickness on Human chorionic gonadotropin injection days is more suitable for implantation of germ cell, and their pregnancy rate, serum hormone levels, follicular development, ovulation and endometrial growth were superior to than those who only treated with letrozole. Moreover, this method can also take advantage of the respective advantages of Chinese and Western medicine, make the best of each other's strengths, treat both the symptoms and the root causes, and improve the clinical pregnancy rate. In the future research, it is necessary to combine the physiology, pathology and other multidisciplinary discussions to propose a more effective treatment plan.
\end{abstract}

Key words: Ovulation induction, ovulation disorders, infertility, pregnancy

Infertility has become a public health issue of common concern worldwide. The incidence rate is increasing year by year. According to the World Health Organization (WHO), infertility will become the third largest category of diseases in the $21 \mathrm{st}$ century after tumors and cardiovascular disease ${ }^{[1-3]}$. Its influence has spread contagiously, which not only has a serious impact on family happiness and personal quality of life, but also has an unmeasurable negative effect on the level of medical services, reproductive health and social, economic and cultural levels in the country and the region. At present, there is no uniform standard for the course of infertility, and different countries or organizations define it differently. WHO defines infertility as: no conception after at least $1 \mathrm{y}$ of marriage with normal sex life and no contraceptive measures were taken. According to statistics, the annual prevalence of infertility in developed countries such as Europe and the United States is $3.5 \%$ to $16.7 \%$, and in developing countries is $6.9 \%$ to $9.3 \%$. The proportion of infertility in China is initially reported as $11 \%{ }^{[4-6]}$.

Ovulation disorders are one of the main causes of infertility, accounting for about $25 \%$ to $30 \%$. Due to mental stress, overwork, hypothalamic, pituitary, ovarian or thyroid, adrenal gland diseases, etc., the Hypothalamic-pituitary-ovarian axis (HPOA) and its associated endocrine glands are dysfunctional, resulting in follicular development, maturation or discharge disorders, which mainly manifested as follicular dysplasia, or stagnation of a certain stage, atresia in follicular development, no dominant follicle, or mature follicles do not rupture, or insufficient luteal function after follicles are discharged.

At present, clomiphene, Letrozole (LE) and other ovulation-promoting medicines are mainly used in modern medicine treatment for treating ovulation disorders infertility, stimulating HPOA, and promoting

*Address for correspondence

E-mail: linshaohua197611@163.com

Special Issue 8, 2020 
follicular growth and development. Western medicine often uses ovulation induction medicine to treat this disease. LE is another ovulation-promoting medicine that has attracted more and more attention. LE is the third-generation aromatase inhibitor. A large number of clinical studies have found that it has the effect of promoting follicular growth, and is gradually used in ovulation treatment for infertility patients with ovulation disorders. For the first time, Mitwally successfully applied it to cases where clomiphene citrate failed to induce ovulation, and the effect of ovulation induction was widely recognized ${ }^{[7-9]}$. In this study, the different ovulation induction medicines are studied and different ovulation induction programs are explored, which is important to reach clinical pregnancy in patients with ovulatory infertility. It also objectively judges the clinical efficacy of the medicine and finds practical evidence for clinical medicine use.

\section{MATERIALS AND METHODS}

\section{General information:}

82 infertility patients in Guangxi International Zhuang Nationality Hospital from January 2013 to December 2018 were elected for this study. All patients were randomly divided into experimental group and control group, with 41 cases in each group. The age of patients in the experimental group was from 20 to $40 \mathrm{y}$ old, with an average of $28.75 \pm 3.55 \mathrm{y}$ old. The age of patients in control group was from 21 to $40 \mathrm{y}$ old with an average of $29.02 \pm 3.48$. There was no significant difference in the baseline distribution between the two groups $(p>0.05)$, which was comparable. The age distribution of the two groups of patients is shown in fig. 1. The infertility course of the experimental group was 1 to $8 \mathrm{y}$, and the average course of disease was 1.79 $\pm 1.15 \mathrm{y}$. The infertility course of the control group was 1 to $8 \mathrm{y}$, and the average course of disease was 1.88 $\pm 1.22 \mathrm{y}$. There was no significant difference in the baseline of the two groups ( $>0.05)$, which was comparable. The distribution of disease course of the two groups is shown in fig. 2.

Sampling inclusion standards: Patients whose age is between 20 and 40 y old; Patients who are in line with the diagnostic criteria for infertility; Patients who are in line with diagnostic criteria of anovulatory abnormal uterine bleeding, polycystic ovary syndrome, hyperprolactinemia, unruptured follicular luteinization syndrome, insufficient corpus luteum function and ovarian reserve function decline/premature ovarian failure; Patients who did not use other medicines; Patients who are willing to participate in the study and can actively cooperate with the follow-up and complete clinical observers.

Exclusion standards: Infertility caused by congenital physiological defects or malformations; Infertility caused by genetic factors; Infertility that is confirmed to be caused by the fallopian tube factor, immune factors, uterine fibroids, uterine muscle adenopathy, endometriosis, or infertility caused by uterine dysplasia; Patients with severe abnormalities in blood vessels, liver, kidney or hematopoietic system, or mental disease.

\section{Treatment method:}

In the experimental group, clomiphene was used together with LE. Clomiphene was orally administered from the 5 th $\mathrm{d}$ of the menstrual cycle, $50 \mathrm{mg}$ each time, once a day for $5 \mathrm{~d}$. If the patient has amenorrhea, progesterone should be taken and then clomiphene on the 5th $\mathrm{d}$ after withdrawal bleeding. If the patient has ovulation after treatment but is not pregnant, the

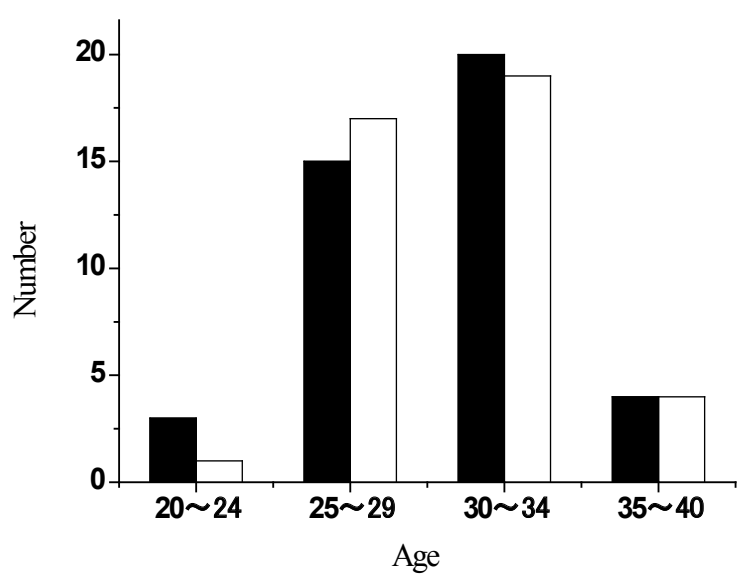

Fig. 1: Age distribution of the two groups of patients Experimental group ( $\square$ ), control group ( $\square$ )

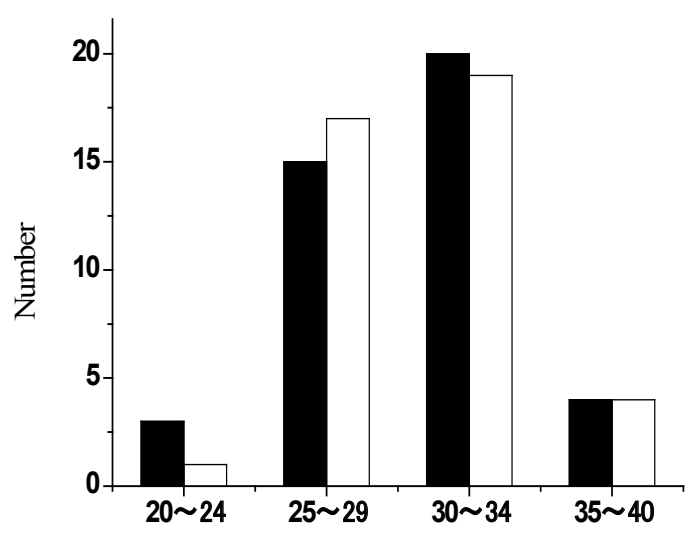

Fig. 2: Disease course distribution of the two groups of patients Experimental group ( $\square$ ), control group ( $\square$ ) 
original treatment can be repeated until pregnancy, or repeat 3-4 courses. If the patient does not ovulate after treatment, the dose can be increased to $100 \mathrm{mg} / \mathrm{d}$ for the next $5 \mathrm{~d}$ for a total of $5 \mathrm{~d}$. LE was orally administered from the 5th $\mathrm{d}$ of the menstrual cycle or the 5 th $\mathrm{d}$ of withdrawal bleeding, $2.5 \mathrm{mg}$ each time, 2 times a day, 1 capsule each time for $5 \mathrm{~d}$.

In the control group, only LE was given. The medicine usage was oral from the 5 th $\mathrm{d}$ of the menstrual cycle or the 5 th $\mathrm{d}$ of withdrawal bleeding, $2.5 \mathrm{mg}$ each time, 2 times a day, 1 capsule each time, for $5 \mathrm{~d}$.

In the meantime, two groups of patients take the medicine using vaginal B-mode (brightness mode) ultrasound to monitor the maximum follicle diameter. If there is a dominant follicle, the patient is instructed to have sex life round ovulatory period. The next course of treatment begins at the next menstruation. Each menstruation is a course of treatment, observing 6 courses of treatment, if the patient is pregnant, then stop taking the medicine. If the patient has delayed menstruation for more than $7 \mathrm{~d}$, excluding the pregnancy, use progesterone capsules orally, $0.2 \mathrm{~g}$ each time, once a night for $7 \mathrm{~d}$, and start taking the medicine on the 5th $\mathrm{d}$ of withdrawal bleeding, the usage is the same as above.

\section{Efficacy evaluation criteria:}

Criteria for comprehensive clinical efficacy: Recovery: After the treatment, the menstrual cycle, the amount of menstruation get normal, the clinical symptoms were significantly improved, B-mode ultrasound monitoring of mature follicles and pregnancy; Effective: After the treatment, the menstrual cycle and the amount of menstruation improved; other clinical symptoms improved, B-mode ultrasound monitoring of mature follicles discharged in 2-3 menstrual cycles; Invalid: After the treatment, no improvement in menstrual conditions, no other clinical symptoms improved, B-mode ultrasound monitoring $\leq 1$ follicle discharged ${ }^{[10-12]}$.

Total effective rate=Cure number+Effective number/ Total number $\times 100 \%$

\section{Determination of ovulation:}

Follicular monitoring: Follicular monitoring was started on the 10th $\mathrm{d}$ of menstruation of normal menstruation or hormonal withdrawal bleeding, once every other once a day until ovulation signs appeared and record day. Once the follicle diameter was $>15 \mathrm{~mm}$, monitor

the diameter of dominant follicle and endometrial thickness on ovulation day. If the follicle monitoring finds the follicle is abnormally large or the follicular development is poor and the dominant follicle is not formed, then stop the monitoring $1 \mathrm{w}$ later after the expected ovulation day. Ovulation signs: Observing the disappearance of continuous enlarged dominant follicles or shrink of the follicle volume, the follicular wall collapses, there is a light spot in the follicle, and there is effusion in the uterus rectum ${ }^{[13-15]}$.

\section{Statistical method:}

The Statistical Package for the Social Sciences (SPSS) 22.0 statistical software was adopted to statistically analyze the symptom scores before and after treatment. The count data was expressed in $\mathrm{n} / \%$ and tested with $\mathrm{X}^{2}$. The measurement data was expressed by $x \pm s$ and tested with $t$. The difference is statistically significant if $\mathrm{p}<0.05$.

\section{RESULTS AND DISCUSSION}

Using LE combined with clomiphene not only have direct effect on the ovary, but also exert its effect on the ovary through the HPOA to improve the microcirculation of the body, increase the blood flow in the ovary, and stimulate the mature follicle ovulation. Clomiphene can compete with estrogen for receptors to block the negative feedback regulation of endogenous estrogen, increase the release of gonadotropin-releasing hormone from the hypothalamus, stimulate the secretion of follicle stimulating hormone, and facilitate the development and discharge of follicles. The study found that the total effective rate of the experimental group was $87.8 \%$, significantly higher than the control group of $73.2 \%$, the difference was statistically significant $(\mathrm{p}<0.05)$, as shown in Table 1 .

Because LE does not consume estrogen receptors, it does not antagonize the action of estrogen, does not affect cervical mucus traits, so the cervical mucus is in good condition and is conducive to sperm through the cervix enter into the uterine cavity, and LE does not affect endometrial development, the endometrium

TABLE 1: COMPARISON OF CLINICAL OUTCOMES BETWEEN THE TWO GROUPS $(\mathrm{N}=41)$

\begin{tabular}{lcccc}
\hline Group & Cure Effective & Invalid & $\begin{array}{c}\text { Total effective } \\
\text { rate }\end{array}$ \\
\hline $\begin{array}{l}\text { Experimental } \\
\text { group }\end{array}$ & 20 & 16 & 5 & $87.8 \%$ \\
Control group & 13 & 17 & 11 & $73.2 \%$ \\
$x^{2}$ & - & - & - & 7.866 \\
$\mathrm{p}$ & - & - & - & $<0.05$ \\
\hline
\end{tabular}


can also be fully grown, with good tolerance, reducing immune rejection, creating good conditions for embryo implantation, which is more conducive to embryo implantation and development.

This study compared the ovulation induction effects of two different regimens. The study found that the number of mature follicles was $(1.20 \pm 0.45)$ in experimental group, and that of the control group was $(1.08 \pm 0.35) \quad(\mathrm{t}=2.04, \mathrm{p}>0.05)$. The difference was not statistically significant. The thickness of the endometrium on HCG injection days was $(0.92 \pm 0.23)$ $\mathrm{cm}$ in the experimental group and $(0.80 \pm 0.21) \mathrm{cm}$ in the control group. The difference between the two groups was statistically significant $(\mathrm{t}=1.01, \mathrm{p}<0.05)$, indicating that in the experimental group, patient's endometrium is more suitable for implantation of germ cell. According to the data analysis of this study, the application of LE combined with clomiphene should be used in the treatment of ovulatory infertility, which makes the endometrial development better. This may be related to the fact that both medicines do not inhibit the endometrium and promote the growth of the endometrium. The ovulation status of the two groups of patients is shown in Table 2.

After the treatment, 41 patients in the experimental group recovered 94 menstrual cycles, of which 76 ovulation cycles occurred, and the ovulation rate was $80.9 \%$. In the control group, 41 patients recovered 85 menstrual cycles, of which 54 ovulation cycles occurred, and the ovulation rate was $63.5 \%$. Comparing the ovulation rate of the two groups, the difference was statistically significant $(p<0.05)$, as shown in fig. 3. Among 41 patients in the experimental group, the number of pregnancy cases was 19 , and the pregnancy rate was $46.34 \%$. Among 41 patients in the control group, the number of pregnancy cases was 8 and the pregnancy rate was $19.51 \%$. Comparing the pregnancy rates of the two groups, the difference was statistically significant $(\mathrm{p}<0.05)$, shown in fig. 4 . It can be concluded that after treatment with LE together with clomiphene therapy,

TABLE 2: COMPARISON OF OVULATION BETWEEN THE TWO GROUPS $(\mathrm{N}=41)$

\begin{tabular}{lcc}
\hline Group & $\begin{array}{c}\text { Number of mature } \\
\text { follicles }\end{array}$ & $\begin{array}{c}\text { Endometrial } \\
\text { thickness on HCG } \\
\text { days }(\mathbf{c m})\end{array}$ \\
\hline Experimental & $1.20 \pm 0.45$ & $0.92 \pm 0.23$ \\
group & $1.08 \pm 0.35$ & $0.80 \pm 0.21$ \\
Control group & 2.04 & 1.01 \\
$t$ & $>0.05$ & $<0.05$ \\
$\mathrm{p}$ & &
\end{tabular}

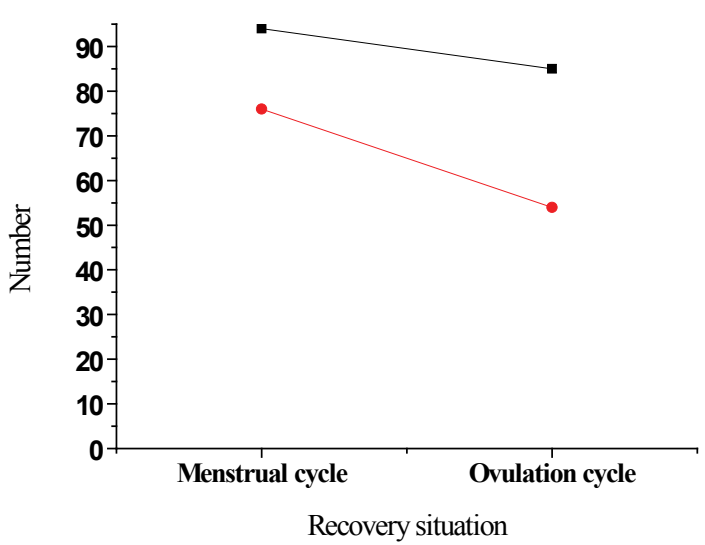

Fig. 3: Comparison of ovulation in the two groups

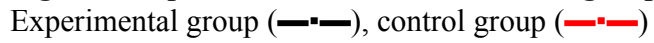

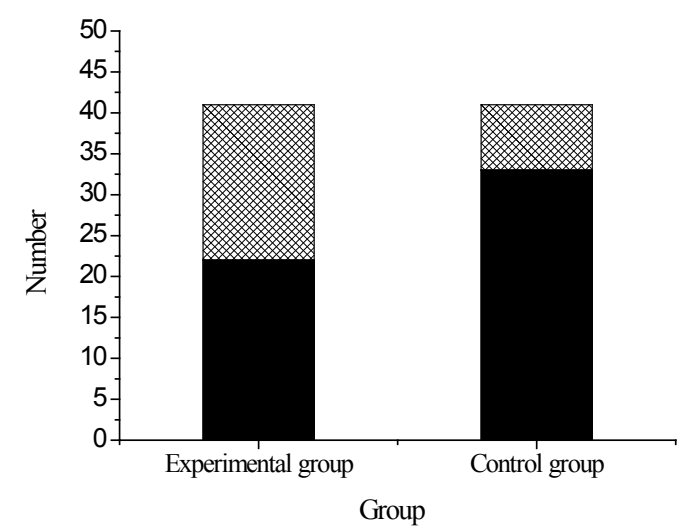

Fig. 4: Comparison of pregnancy rates in the two groups Pregnancy ( $x_{x}$ ) No pregnancy (

the ovulation rate and pregnancy rate of patients are significantly higher than use LE alone.

Infertility is defined as no conception within $1 \mathrm{y}$ if cohabiting couples living together with normal sexual life, and without any contraception methods, or no conception within $1 \mathrm{y}$ for couple who have pregnancy before with normal sexual life, and without any contraception methods. Ovulation disorders include anovulation and luteal phase defect. The main reason for anovulation is due to functional or organic abnormalities of the HPOA. Luteal phase defect refers to the deficiency of progesterone secretion in the corpus luteum or atrophy of premature corpus luteum.

Clomiphene is the most widely used ovulationpromoting medicine in clinical practice. It can promote the secretion of gonadotropin, effectively increase the number of mature follicles, and promote the discharge of follicles, which improves the pregnancy rate to some extent. Clomiphene can't directly promote the growth of follicles, but by stimulating the estrogen receptor, regulating the hypothalamic-pituitary-ovarian 
reproductive axis to play a role in promoting ovulation, and is suitable for those with certain estrogen levels in the body. Therefore, although clomiphene ovulation promotes ovulation and the ovulation rate is high, the pregnancy rate can't achieve the desired effect. LE bring down the concentration of estrogen by inhibiting aromatase in the body, thereby relieving the negative feedback inhibition of estrogen on the hypothalamus and pituitary, it also secretes Follicle-stimulating hormone (FSH), promoting follicular development and ovulation; in addition, it can block the conversion of androgen to estrogen and causes the androgen to accumulate in the ovary, increasing the sensitivity of the follicle to $\mathrm{FSH}$, and makes the follicle to grow to achieve the purpose of promoting ovulation.

In this study, the effects of LE combined with clomiphene and usage of LE alone on patients with ovulatory infertility are compared, and it is found that the combination of medicines is more effective in promoting ovulation, which can effectively improve the pregnancy rate of patients with ovulatory infertility. However, there are few samples in this study, and the experimental design is relatively simple, lacking multidisciplinary coordination such as physiology, pathology and genetics. It is expected that in the future research, the rigor of thinking, design multidisciplinary participation, and develop long-term follow-up plans and more representative clinical research can be improved.

\section{Acknowledgement:}

None

\section{Conflict of Interests:}

The authors declared no conflict of interest.

\section{REFERENCES}

1. Lauritsen MP, Loft A, Pinborg A, la Cour Freiesleben N, Cohen A, Petersen $\mathrm{JH}$, et al. Individualised gonadotrophin ovulation induction in women with normogonadotrophic anovulatory infertility: A prospective, observational study. Eur J Obstet Gynecol Reprod Biol 2017;210:76-82.

2. Jie L, Li D, Yang C, Haiying Z. Tamoxifen versus clomiphene citrate for ovulation induction in infertile women. Eur J Obstet Gynecol Reprod Biol 2018;228:57-64.

3. Practice Committee of the American Society for Reproductive Medicine. Role of metformin for ovulation induction in infertile patients with polycystic ovary syndrome (PCOS): a guideline. Fertil Steril 2017;108(3):426-41.

4. Braam SC, de Bruin JP, Buisman ET, Brandes M, Nelen WL, Smeenk JM, et al. Treatment strategies and cumulative live birth rates in WHO-II ovulation disorders. Eur J Obstet Gynecol Reprod Biol 2018;225:84-9.

5. Kahyaoglu S, Yilmaz B, Is1k AZ. Pharmacokinetic, pharmacodynamic, and clinical aspects of ovulation induction agents: A review of the literature. J Turk Ger Gynecol Assoc 2017;18(1):48-55.

6. Chen L, Tan Y, Chen SP. Effect of clomiphene citrate and Dingkun Dan on ovulation induction and clinical pregnancy of polycystic ovary syndrome. Chin J Chin Materia Medica 2017;42(20):4035-9.

7. Goel T, Mahey R, Bhatla N, Kalaivani M, Pant S, Kriplani A. Pregnancy after endometrial scratching in infertile couples undergoing ovulation induction and intrauterine insemination cycles-A randomized controlled trial. J Assist Reprod Genet 2017;34(8):1051-8.

8. Green KA, Zolton JR, Schermerhorn SM, Lewis TD, Healy MW, Terry N, et al. Progesterone luteal support after ovulation induction and intrauterine insemination: an updated systematic review and meta-analysis. Fertil Steril 2017;107(4):924-33.

9. Agrawal K, Gainder S, Dhaliwal LK, Suri V. Ovulation induction using clomiphene citrate using stair-step regimen versus traditional regimen in polycystic ovary syndrome women-a randomized control trial. J Hum Reprod Sci 2017;10(4):261-4.

10. Vrisman DP, Bastos NM, Rossi GF, Rodrigues NN, Borges LP, Taira AR, et al. Corpus luteum dynamics after ovulation induction with or without previous exposure to progesterone in prepubertal Nellore heifers. Theriogenology 2018;106:60-8.

11. Del Pup L, Peccatori FA. Is ovulation induction with letrozole in breast cancer patients still safe even if it could increase progesterone levels. Eur Rev Med Pharmacol Sci 2018;22(1):246-9.

12. Bordi G, D'Ambrosio A, Gallotta I, Di Benedetto L, Frega A, Torcia F, et al. The influence of ovulation induction and assisted conception on maternal and perinatal outcomes of twin pregnancies. Euro Rev Med Pharmacol Sci 2017;21:39984006.

13. Chen M, Han H, Chuai Y, Hao M, Shu M, Shang W. Effects of oral contraceptives on ovulation induction in in vitro fertilization patients with premature ovarian insufficiency. Climacteric 2018;21(3):276-9.

14. Chen CR, Yan QX, Zhou XQ, Xian YJ, Guo XY, Quan S. Effects of raloxifene at two different doses for ovulation induction on endometrial pinopodes in mice during the implantation window. J South Med Univ 2018;38(2):234-8.

15. Katler Q, Pflugner L, Martinez A. Management of bilateral ectopic pregnancies after ovulation induction using unilateral salpingectomy and methotrexate for the remaining ectopic with subsequent intrauterine pregnancy. Case Rep Obstet Gynecol 2018:1-4.

This is an open access article distributed under the terms of the Creative Commons Attribution-NonCommercial-ShareAlike 3.0 License, which allows others to remix, tweak, and build upon the work non-commercially, as long as the author is credited and the new creations are licensed under the identical terms

This article was originally published in a special issue, "Trends in Therapeutic Management of Various Clinical Conditions II" Indian J Pharm Sci 2021:83(2)Spl issue;36-40 